\title{
PERANCANGAN APLIKASI SISTEM PAKAR DIAGNOSA DIABETES DENGAN METODE BAYES
}

\author{
Hengki Tamando Sihotang \\ Teknik Informatika \\ STMIK Pelita Nusantara, Jl. IskandarMuda No 1 Medan, Sumatera Utara, Indonesia 20154 \\ hengki_tamando@yahoo.com .
}

\begin{abstract}
Abstak
Deteksi secara dini dapa meminimalisi resiko kematian penderita Diabetes Mellitus serta untuk penanganan awal penyakit ini. Proses deteksi yang ada selama ini masih manual, hal ini bergantung pada pakar penyakit organ dalam tubuh manusia yang jumlahnyatergolongterbatassertabiayadiagnosa yang relatifmahal. Akan tetapi, banyakmasyarakat yang belum memiliki kesadaran yang tinggi akan bahaya penyakit ini dan juga tidak mempunyai pengetahuan dasar mengenai penyak it ini serta mengalami keterbatasan waktu sehingga jarang melakukan konsultasi kepada dokter. Oleh karena itu, diperlukan sebuah sistem pakar yang dapat menggantikan peran seorang dokter dan memberikan edukasi pengetahuan-pengetahuan umum mengenai diabetes mellitus kepada masyarakat.Tujuan dari penelitian ini adalah merancang $\mathrm{d}$ an membangun sebuah sistem pakar yang dapat mendeteksi kemungkinan menderita diabetes mellitus. berdasarkan gejala-gejala yang telah dimasukkan serta memberikan rekomendasi berupa informasi dan solusi terhadap penyakit tersebut. Salah satu metode yang dapat digunakan dalam perhitungan probabilitasnya adalah metode Bayes.Metode ini merupakan sebuah pendekatan untuk sebuah ketidak tentuan yang diukur dengan probabilitas. Berdasarkan hasil analisa, sistem ini dapat menangani proses konsultasi pengguna dengan tingkat akurasi yang cukup tinggi.
\end{abstract}

Kata Kunci: Bayes, diabetes mellitus, sistempakar

\begin{abstract}
Abstrack
Early detection can minimize the risk of death of Diabetes Mellitus sufferers and for early treatment of this disease. The existing detection process is still manual, it depends on experts in organ disease in the human body that the number is quite limited and the cost of diagnosis is relatively expensive. However, many people who do not yet have a high awareness of the dangers of this disease and also do not have basic knowledge about this disease and have limited time so rarely consult a doctor. Therefore, it takes an expert system that can replace the role of a doctor and educate general knowledge about diabetes mellitus to the community. The purpose of this study is to design and build an expert system that can detect the possibility of diabetes mellitus. based on the symptoms that have been included and provide recommendations in the form of information and solutions to the disease. One method that can be used in the calculation of probability is Bayes method. This method is an approach to an uncertainty as measured by probability. Based on the results of the analysis, this system can handle user consultation process with a fairly high level of accuracy.
\end{abstract}

Keywords: Bayes, diabetes mellitus, expert system

\section{PENDAhuluan}

Diabetes melitus merupakan penyakit menahun yang dapat diderita seumur hidup. DM akan memberikan dampak terhadap kualitas sumber daya manusia dan peningkatan biaya kesehatan yang cukup besar. Akan tetapi, tingkat kesadaran masyarakat akan dampak buruk yang ditimbulkan oleh DM masih rendah dan banyak masyarakat yang tidak menyadari dirinya sedang berada dalam resiko diabetes mellitus. Salah satu penyebabnya adalah kurangnya pengetahuan tentang diabetes mellitus dan juga keterbatasan waktu maupun biaya untuk konsultasi ke dokter. Oleh karena itu, perlu adanya sebuah media edukasi ke pada pasien dan keluarganya yang bertujuan untuk memberikan pemahaman mengenai gejala, pencegahan, dan informasi umum seputar DM.

Teknologi komputer pada bidang system pakar yang sangat pesat, hasil dari pemikiran dan pelatihan pakar dapat diadopsi dengan menggunakan teknologi Kecerdasan Buatan (Artificial Intelligence), khususnya sistem pakar. 
Komputer dapat bertindak sebagai konsultan yang cerdas dalam lingkungan keahlian tertentu sebagai hasil dari himpunan pengetahuan dari beberapa orang pakar. Dengana danya sistem pakar, proses konsultasi akan menjadi lebih mudah, efektif dan efisien. Metode yang digunakan dalam kasus ini adalah metode Bayes. Metode ini merupakan sebuah pendekatan untuk sebuah ketidak tentuan yang diukur dengan probabilitas. Pendekatan Bayes pada saat klasifikasi adalah mencariprobabilitas tertinggi dengan masukan atribut-atribut yang diperlukan serta kemungkinan dari penyakit dan gejala-gejala yang berkaitan.

Oleh karena itu, kebutuhan informasi yang cepat dan tepat dari seorang pakar kesehatan sangatlah dibutuhkan.Gejala yang awalnya hanya dalam bentuk manual kemudian dikomputerisasikan menggunakan bahasa pemrograman PHP (Hypertext Preprocessor) agar memudahkan masyarakat dalam mendeteksi penyakit diabetes mellitus sejak dini. Manfaat penilitian ini antara lain : masyarakat dapat berkonsultasi langsung untuk mendiagnosa penyakit diabetes mellitus pada Klinik Aviati Medan sehingga berkurangnya penderita penyakit diabetes mellitus.

\section{METODE BAYES}

Metode Bayes merupakan pendekatan statistic untuk melakukan inferensi induksi pada persoalan klasifikasi. Metode ini menggunakan probabilitas bersyarat sebagai dasarnya. Dalam ilmustatistik, probabilitas $\mathrm{X}$ di dalam $\mathrm{Y}$ adalah probabilitas inteseksi X dan Y dari probabilitas Y, atau dengan bahasa lain

$\mathrm{P}(\mathrm{X} \mid \mathrm{Y})$ adalah presentase banyaknya $\mathrm{X}$ didalam $\mathrm{Y}$. Adapun Formula Bayesan dinyatakan sebagai berikut. [1]

dimana :

$(B \mid A)=$ Peluang $\mathrm{B}$ jika diketahui keadaan jenis penyakit A.

$(A \mid B)=$ Peluang evidence $\mathrm{A}$ jika diketahui hipotesis $\mathrm{B}$

$(B)=$ Probabilitashipotesis $\mathrm{B}$ tanpa memandang evidence apapun

$(A)=$ Peluang evidence penyakit A.

Secara umum, teorema Bayesian dengan E kejadian dan hipotesis $\mathrm{H}$ dapat dituliskan dalam bentuk persamaan berikut.

$\mathrm{P}(\mathrm{Hi} \mid \mathrm{E})=\frac{P\left(E^{n} H\right)}{\sum P\left(E^{n} H \mathrm{Hi}\right)}$

$$
\begin{aligned}
& \mathrm{P}(\mathrm{Hi} \mid \mathrm{E})=\frac{P(E) \mid H i)_{P} P(H i)}{\sum P(E) \mid H D \cdot P(H i)} \\
& \mathrm{P}(\mathrm{Hi} \mid \mathrm{E})=\frac{P(E \mid H i) P(H i)}{P(E)} \\
& \mathrm{P}(\mathrm{Hi} \mid \mathrm{E})=\frac{P[E \| H \mathrm{D}) P(H i)}{\sum_{k=1}^{n} P(\varepsilon \mid H k) \cdot P(H k)}
\end{aligned}
$$

Probabilitas menunjukkan kemungkinan sesuatu akan terjadi atau tidak. Untuk menghitung probabilitas ditunjukkan dengan persamaan :

$\mathrm{P}(\mathrm{x})=\frac{\text { jumlah kejadian berhasil }}{\text { jumlah semua kejadian }}$

$P(x)=$ probabilitas terjdinya $x$

Contoh kasus penyakit diabetes mellitus:

Asta memilih gejala penyakit Diabetes untuk mendapat hasil diagnosanya. Asta memilih gejala sebagai berikut :

\begin{tabular}{|c|c|c|c|}
\hline \multicolumn{4}{|c|}{ Gejala Bobot Peluang Penyakit } \\
\hline G1 & 0.5 & $\mathrm{P}(\mathrm{E} \mid \mathrm{H} 1)$ & $\begin{array}{l}\text { polipuria } \\
\text { (banyakkencing)? }\end{array}$ \\
\hline G2 & 0.3 & $\mathrm{P}(\mathrm{E} \mid \mathrm{H} 2)$ & $\begin{array}{l}\text { Polidipsia } \\
\text { (banyakminum)? }\end{array}$ \\
\hline G3 & 0.3 & $\mathrm{P}(\mathrm{E} \mid \mathrm{H} 3)$ & $\begin{array}{l}\text { Polifagia } \\
\text { (banyakmakan)? }\end{array}$ \\
\hline G4 & 0.1 & $\mathrm{P}(\mathrm{E} \mid \mathrm{H} 4)$ & $\begin{array}{l}\text { Kram } \\
\text { (seringterjadikramp } \\
\text { adaotot)? }\end{array}$ \\
\hline G5 & 0,5 & $\mathrm{P}(\mathrm{E} \mid \mathrm{H} 5)$ & $\begin{array}{l}\text { Semutan } \\
\text { kesemutan)? }\end{array}$ \\
\hline
\end{tabular}

TABEL I.

GEJALA DAN BOBOT

Kemudian mencari nilai semesta dengan menjumlahkan dari hipotesa di atas :

$$
\begin{aligned}
=\mathrm{G} 1+\mathrm{G} 2+\mathrm{G} 3+\mathrm{G} 4+\mathrm{G} 5+\mathrm{G} 6+\mathrm{G} 7+ \\
=0.5+0.3+0.3+0.1+0,5=8,1
\end{aligned}
$$

Setelah hasil penjumlahan di atas diketahui, maka didapatlah rumus untuk menghitung nilai semesta adalah sabagai berikut :

$$
\begin{array}{ll}
\mathrm{P}(\mathrm{H} 1)= & =0.061 \\
\mathrm{P}(\mathrm{H} 2)= & =0.037 \\
\mathrm{P}(\mathrm{H} 3)= & =0.037 \\
\mathrm{P}(\mathrm{H} 4)= & =0.123 \\
\mathrm{P}(\mathrm{H} 5)= &
\end{array}
$$


Setelah nilai $\mathrm{P}$ (Hi) diketahui, probabilitas hipotesis $\mathrm{H}$ tanpa memandang evidence apapun, makalangkah selanjutnyaadalah :

$$
\begin{aligned}
& P(H i) * P E(H i-n) \\
& \mathrm{P}(\mathrm{H} 3) * \mathrm{P}(\mathrm{E} \mid \mathrm{H} 3)+\mathrm{P}(\mathrm{H} 4) \text { * } \\
& \mathrm{P}(\mathrm{E} \mid \mathrm{H} 4)+\mathrm{P}(\mathrm{H} 5) * \mathrm{P}(\mathrm{E} \mid \mathrm{H} 5) \\
& 0.0955 \\
& \mathrm{P}(\mathrm{H} 1 \mid \mathrm{E})=\quad=0.31937 \\
& \mathrm{P}(\mathrm{H} 2 \mid \mathrm{E})=\quad=0.11623 \\
& \mathrm{P}(\mathrm{H} 3 \mid \mathrm{E})=\quad=0.11623 \\
& \mathrm{P}(\mathrm{H} 4 \mid \mathrm{E})=\quad=0.31937 \\
& \mathrm{P}(\mathrm{H} 5 \mid \mathrm{E})=\quad=0,31937
\end{aligned}
$$$$
=\mathrm{P}(\mathrm{H} 1) * \mathrm{P}(\mathrm{E} \mid \mathrm{H} 1)+\mathrm{P}(\mathrm{H} 2) * \mathrm{P}(\mathrm{E} \mid \mathrm{H} 2)+
$$$$
=(0.061 * 0.5)+(0.037 * 0.3)+
$$$$
(0.037 * 0.3)+(0.1233 * 0.1)+(0.13661 * 0.5)=
$$

Langkah selanjutnya ialah mencari nilaiP(Hi|E) atau probabilitas hipotesis Hi benar jikadiberikan

Setelah seluruh nilai $\mathrm{P}$ (Hi|E) diketahui, maka jumlahkan seluruh nilai bayesnya dengan rumus sebagai berikut :

Bayes1 + Bayes2 + Bayes 3 + Bayes 4 Bayes 5

$=(0.5 * 0.31937)+(0.3 * 0.11623)+(0.3 * 0.11623)$

$+(0.1 * 0.12879)+(0.5 * 0.31937)$

$=0.3903959 * 100 \%$

$=3903959 \%$

Dari kesimpulan perhitungan di atas, maka dapat dipastikan Aulia menderita penyakit diabetes mellitus dengan nilai39.03959\%

\section{III.HASIL DAN PEMBAHASAN}

\section{A. ImplementasiSistem}

Setelah sistem dianalisis dan didesain secara rinci, maka akan menuju tahap implementasi. Implementasi sistem merupakan tahap meletakkan sistem sehingga siap untuk dioperasikan. Implementasi bertujuan untuk mengkonfirmasi modul-modulperancangan, sehingga pengguna dapat memberi masukan kepada pengembangan

\begin{tabular}{|c|c|c|}
\hline No & Nama Software & Fungsi \\
\hline 2 & XAMPP & $\begin{array}{l}\text { Aplikasi server locak untuk } \\
\text { PHP dan database My-SQL }\end{array}$ \\
\hline 3 & $\begin{array}{l}\text { Mozila Firefox } \\
\text { /Crhome }\end{array}$ & $\begin{array}{ll}\text { Browser } & \text { untuk } \\
\text { menjalankan apliksi }\end{array}$ \\
\hline 4 & $\begin{array}{l}\text { Adobe } \\
\text { Dreamweaver } \\
\text { CS5 }\end{array}$ & $\begin{array}{l}\text { Editor web untuk HTML, } \\
\text { PHP dan Javascript }\end{array}$ \\
\hline 5 & Artister & $\begin{array}{l}\text { Software } \\
\text { Template }\end{array}$ \\
\hline
\end{tabular}
sistem.

Setelah melakukan tahap perancangan sistem dan implementasi perangkat lunak, maka tindakan selanjutnya yang dilakukan adalah penerapan hasil perangkat lunak tersebut.

1. Kebutuhan Perangkat Lunak

TABEL II.

KEBUTUHAN PERANGKAT LUNAK

\begin{tabular}{lllc}
\hline No & Nama Software & \multicolumn{1}{c}{ Fungsi } \\
\hline 1 & OS Windows 7 & Operating & Sistem \\
& & Komputer/laptop &
\end{tabular}

\begin{tabular}{|c|c|c|}
\hline $\begin{array}{c}\text { ID_Gej } \\
\text { ala }\end{array}$ & Penyakit & $\begin{array}{l}\text { Id_Pe } \\
\text { nyakit }\end{array}$ \\
\hline G01 & Polipuria (banyak kencing) & P1 \\
\hline G02 & Polidipsa (banyak minum) & P1 \\
\hline G03 & Polifagia (banyak makan) & P1 \\
\hline G04 & $\begin{array}{l}\text { Kram (sering terjadi kram pada } \\
\text { otot) }\end{array}$ & $\mathrm{P} 1$ \\
\hline G05 & Semutan (rasa kesemutan) & P1 \\
\hline G06 & $\begin{array}{l}\text { Rasa tebal (pada ujung kaki } \\
\text { tangan/kaki) }\end{array}$ & $\mathrm{P} 1$ \\
\hline G07 & Berat badan turun drastic & P1 \\
\hline G08 & $\begin{array}{l}\text { Turun BB tiba-tiba tanpa alasan } \\
\text { jelas }\end{array}$ & $\mathrm{P} 2$ \\
\hline G09 & $\begin{array}{l}\text { Kulit (kelainan pada kulit menjadi } \\
\text { kering) }\end{array}$ & $\mathrm{P} 2$ \\
\hline G10 & Gatal (gatal disekita kemaluan) & $\mathrm{P} 2$ \\
\hline G11 & $\begin{array}{l}\text { Bisul (sering muncul bisul } \\
\text { ditubuh) }\end{array}$ & P2 \\
\hline G12 & Infeksi ( mudah tekena infeksi) & $\mathrm{P} 2$ \\
\hline G13 & $\begin{array}{l}\text { Keputihan (keputihan karena } \\
\text { kelainan pada ginjal) }\end{array}$ & P2 \\
\hline G14 & Luka (luka yang sukar sembuh) & P2 \\
\hline G15 & Lapar (cepat lapar) & P2 \\
\hline G16 & $\begin{array}{l}\text { Gemetar (gemetar } \\
\text { kelebihan lapar) }\end{array}$ & P2 \\
\hline
\end{tabular}

2. Kebutuhan Perangkat Keras

Perangkat Keras yang digunakan dalam perancangan ini adalah satu unit komputer dengan spesifikasi pada tabel berikut:

TABEL III.

KEBUtuhan PERANGKAT KerAs

\begin{tabular}{lllll}
\hline No & Nama Software & Fungsi & \\
\hline 1 & Processor Core 2 & $\begin{array}{l}\text { Processor computer yang } \\
\text { sesuai untuk perancangan } \\
\text { system }\end{array}$ \\
2 & Hardisk & $\begin{array}{l}\text { Hardisk dengan kapasitas } \\
320 \text { GB }\end{array}$ & Memory dengan kapasitas 2 \\
3 & Memory & $\begin{array}{l}\text { GB } \\
\text { Monitor LCD dengan } \\
4\end{array}$ & Monitor LCD & $\begin{array}{l}\text { ukuran 14 inch } \\
\text { Keyboard dan mouse untuk } \\
\text { masukan }\end{array}$ \\
5 & Keyboard & \& & \\
\hline & Mouse & &
\end{tabular}

B. Basis Aturan 


\begin{tabular}{|c|c|c|}
\hline $\begin{array}{c}\text { ID_Gej } \\
\text { ala }\end{array}$ & Penyakit & $\begin{array}{l}\text { Id_Pe } \\
\text { nyakit }\end{array}$ \\
\hline G17 & $\begin{array}{l}\text { Lemah (tubuh terasa cepat lebih } \\
\text { lemah) }\end{array}$ & $\mathrm{P} 2$ \\
\hline G18 & Sering pingsan & P3 \\
\hline G19 & $\begin{array}{l}\text { Keringat (banyak keringat } \\
\text { terutama keringat dingin) }\end{array}$ & P3 \\
\hline G20 & $\begin{array}{l}\text { Berdebar (detakan jantung tidak } \\
\text { normal) }\end{array}$ & P3 \\
\hline G21 & Pusing (sering pusing) & P3 \\
\hline $\mathrm{G} 22$ & Gelisah (suka gelisah) & P3 \\
\hline G23 & Koma (hilang kesadaran) & P3 \\
\hline
\end{tabular}

Basis aturan disesuaikan antara pertanyaan penyakit dengan ID_Gejala dan Id_Gejala. Misal, jika G1, G2, G3, G4, G5 dan G6 maka peluang penyakit yang disimpulkan adalah P1 yaitu penyakit polipuria (banyakkencing).Untuk mengimplementasikan ke program, penyakit 1 disingkat jadi P1, gejala 1 disingkat G1.Misal,gejalaapakahkoma (hilangkesadaran? (G23) digolingkankedalampenyakit P3.

\section{Dasar solusi penyakit diabetes mellitus}

TABEL V.

\begin{tabular}{cl}
\hline \multicolumn{1}{c}{ SOLUSI } \\
\hline ID_Solusi & \multicolumn{1}{c}{ Solusi } \\
\hline S1 & $\begin{array}{l}\text { Dari semua penderita diabetes. 5-10 } \\
\text { persennya adalah penderita diabetes } \\
\text { tipe 1. Di Indonesia. }\end{array}$ \\
S2 & $\begin{array}{l}\text { Sama halnya dengan diabetes tipe 1. } \\
\text { Diabetes tipe2 juga mempunyai nama } \\
\text { lain, Yaitu non insulin } \\
\text { memonitor kadar glukosa dalam } \\
\text { darah,pemeriksaan ultrasound } \\
\text { diet sehat, olah raga }\end{array}$ \\
\hline
\end{tabular}

Keterangan :

Solusi disingkat S. Misal, Pilih dan batasi beberapa jenis olahraga serta konsultasikan dengan profesionalkesehatan atau dokter adalah solusi 11.

\section{Rule Sistem Pakar Diagnosa Penyakit Diabetes Mellitus}

Rule 1

IF gejala : P1

AND Poliuria (banyak kencing)

AND Polidipsia (banyak minum)

AND Polifagia (banyak makan)

AND Konsentrasi (konsentrasi mudah terganggu/kurang fokus)

AND kram (sering terjadi kram pada otot)
AND Semutan (rasa kesemutan)

AND Rasa tebal (pada ujung kaki tangan ato kaki)

AND Berat badan turun drastis

\section{THENDiabetes Tipe 1(S1)}

Rule 2

IF gejala : $\mathrm{P} 2$

AND turun BB tiba-tiba tanpa alasan jelas

AND Gatal (gatal sekitaran kemaluan)

AND kulit (kelainan pada kulit menjadi kering)

AND Bisul (sering muncul bisul ditubuh)

AND Infeksi (mudah terkena infeksi)

AND Keputihan (keputihan karena kelainan pada ginjal kalogi)

AND Luka (luka yang sukar sembuh)

AND Lapar (cepat lapar)

AND Gemetar (gemetar karena kelebihan lapar)

AND Lemah (tubuh cepat terasa lemah)

THENDiabetes Tipe 2 (S2)

Rule 3

IF gejala : P3

ANDsering pingsan

ANDKeringat (banyak keringat, terutama keringat dingin)

AND Berdebar (detakan jantung tidak normal)

AND Pusing (sering pusing)

AND Gelisah (suka gelisah)

AND Koma (hilang kesadaran)

THEN Diabetes Tipe 3 ( melitus gestasional) (S3)

\section{E. Tampilan Aplikasi Sistem Pakar Penyakit Diabetes Mellitus \\ 1. Tampilan Menu Utama}

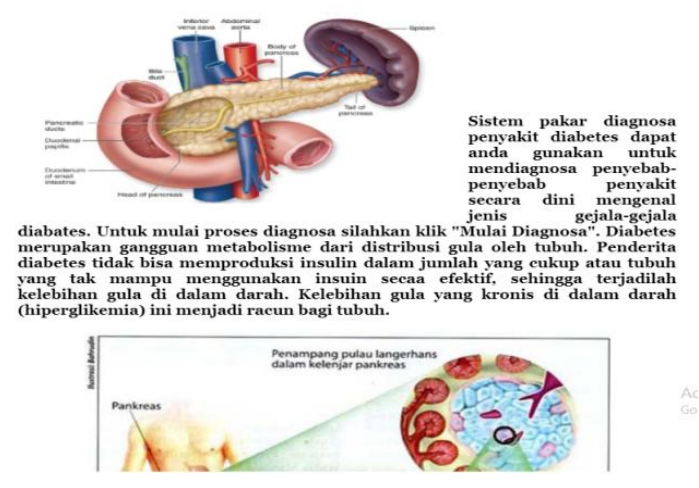

Gambar 1. Menu Utama 
2. Tampilan Login Admin

Perancangan Sistem Pakar Dengan Metode Bayes Diagnosa Diabetes Mellitus

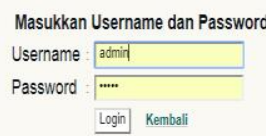

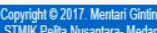

Gambar 2. Login Admin

3. Tampilan Data Gejala

\begin{tabular}{|c|c|c|c|}
\hline \multicolumn{4}{|c|}{ Data Gejala-gejala } \\
\hline \multirow{3}{*}{$\begin{array}{l}\text { Kode gejala } \\
\text { Gejala }\end{array}$} & & & \\
\hline & & & \\
\hline & \begin{tabular}{|l|l|} 
Simpan & Reset \\
\end{tabular} & \multirow[b]{2}{*}{ Edit } & \multirow[b]{2}{*}{ Hapus } \\
\hline Kode Gejala & Gejala & & \\
\hline G01 & Poliura (banyak kencing) & $\square$ & 9 \\
\hline 602 & Polidipsia (banyak minum) & (7) & 9 \\
\hline G03 & Pollfagia (banyak makan) & [ & 9 \\
\hline G04 & Konsenirasi (konsentrasi mudah terganggü/kurang fokus) & 【 & 3 \\
\hline 605 & Kram (sering tejjadi kram pada otot) & (] & 9 \\
\hline 606 & Semutan (rrsa kesemutan) & 回 & 3 \\
\hline G07 & Rasa tebal (pada ujung kaki tangan atau kaki) & 【 & 9 \\
\hline 608 & Berat badan turun drastis & [ & 9 \\
\hline G09 & Turun BB tiba-tiba tanpa alasan jelas & 【 & 9 \\
\hline 610 & Gatal (gatal sekitaran kemaluan) & 回 & 9 \\
\hline G11 & Kultit (kelainan pada kulti menjadi kering) & (๘) & 9 \\
\hline G12 & Bisul (sering muncul bisul ditubuh) & (a) & 9 \\
\hline G13 & Infeksi (mudah terkena infeksi) & 【 & 3 \\
\hline G14 & Keputhan (keputhan karena kelainan pada ginjal kalogi) & 【 & 3 \\
\hline 615 & Luka (luka yang sukar sembuh) & [ & 9 \\
\hline
\end{tabular}

Gambar 3. Data Gejala

4. Tampilan Registrasi Pengguna

\begin{tabular}{|c|c|}
\hline & Biodata Pasien \\
\hline Nama & mulia \\
\hline Jenis Kelamin & - Laki-laki Perempuan \\
\hline Tanggal Lahir & 1971-11-03 yyyy-mm-dd \\
\hline Alamat & petisanh \\
\hline Email & mulia@gmail.com \\
\hline \multirow[t]{2}{*}{ Pekerjaan } & buruh parrik \\
\hline & \begin{tabular}{|l|l|} 
Daftar Reset \\
\end{tabular} \\
\hline
\end{tabular}

Gambar 4. Registrasi Pengguna
5. Tampilan Rule Relasi

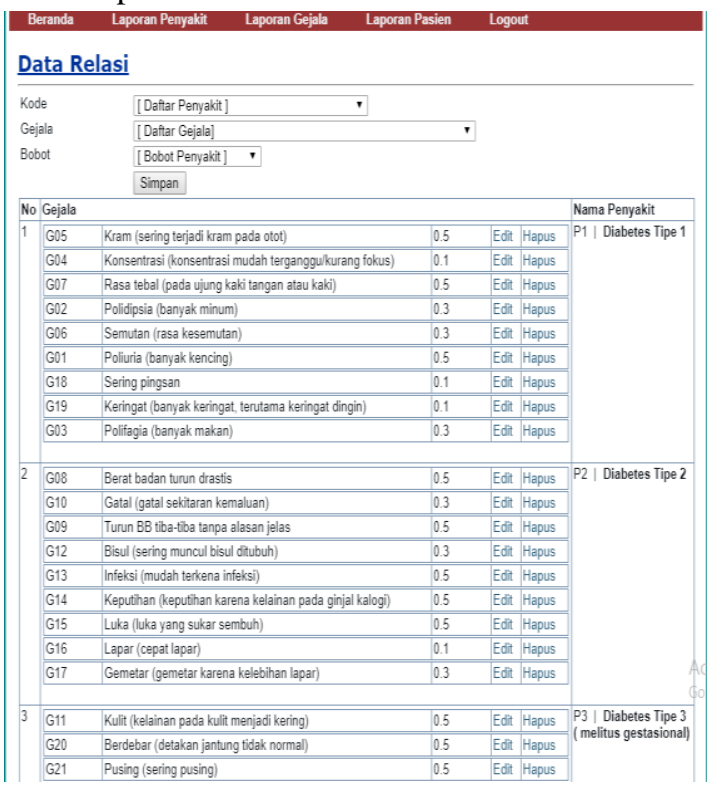

Gambar 5. Rule Relasi

6. Tampilan Hasil Diagnosa

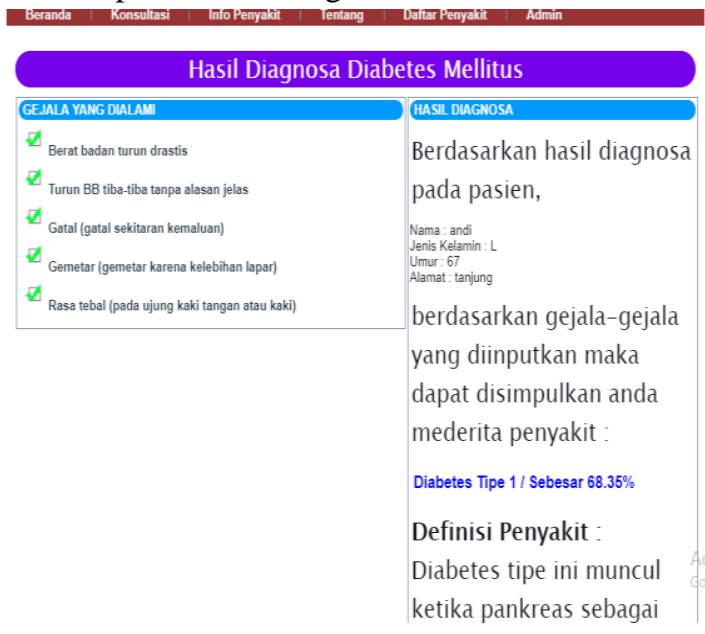

Gambar 6. Hasil diagnosa

\section{KESIMPULAN}

Berdasarkan hasil pembahasan teori pada perancangan sistem pakar diagnosa diabetes mellitus dapat disimpulkan sebagai berikut :

1. Sistem pakar dapat mendiagnosa diabetes merupakan sebuah sistem yang dapat mendiagnosa diabetes yang meliputi diabetes tipe 1, diabetes tipe 2 dan diabetes tipe 3 .

2. Dalam mendiagnosa diabetes setelah ditemukan gejala dan tipe diabetes sistem juga 
mampu memberikan informasi untuk solusi pengobatan penyakit.

3. Sistem yang berbasis web dapat di akses oleh semua pasien diabetes karena sistem yang dijalankan pada aplikasi web.

\section{DAFTAR PUSTAKA}

[1] Asti Marlina, "Metode Bayes Untuk Menentukan Kelayakan Calon Tenaga Kerja Ke Luar Negeri”, Jurnal Ilmiah Teknologi, 2010.

[2] Ari Fadli, “ Sistem Pakar Dasar”, Ilmu Komputer, fadli.te.unsoed@gmail.com, http://fadli84.wordpress.com, 2010.

[3] Ibnu Aqil, "Sistem Informasi Alumni Diploma Pada Bina Sriwijaya Palembang Berbasis Web", Akademi Manajemen Informatika dan Komputer Bina Sriwijaya Palembang, Palembang, 2010.

[4] Detty Purnama sari, et al "Get Easy Using WEKA”, Dapur Buku, Indonesia 2013.

[5] Adhiati Kusuma Wardani, et al "Sistem Pakar Diagnosa Penyakit Diabetes Mellitus “, Teknik Informatika, 2014.

[6] Achmad Rudijanto, et al “ Pengelolaan Dan Pencegahan Diabetes Mellitus Tipe 2 Di Indonesia", Pengurus Besar Perkumpulan Endokrinologi Indonesia, 2015.

[7] IbnuAqil, "Sistem Informasi Alumni Diploma Pada Bina Sriwijaya Palembang Berbasis Web", Akademi Manajemen Informatika dan Komputer Bina Sriwijaya Palembang, Palembang, 2010.

[8] Januar Dwie Amanda, “ Implementasi Metode Dempster-Shafer untuk Mendeteksi Penyakit Diabetes Mellitus, Program Studi Teknik Informatika Universitas Brawijaya, 2014.
[9] Syafudin Ramadani, “ Rancang Bangun Informasi Geografis Layanan Kesehatan Di Kecamatan Lamongan Dengan PHP MysQl”, Program Teknik Informatika Universitas Islam Lamongan, Lamongan, 2013.

[10] Marbun, Murni, et al. "Perancangan Sistem Perencanaan Jumlah Produksi Roti Menggunakan Metode Fuzzy Mamdani." Jurnal Mantik Penusa, vol. 20, no. 1, 2016, pp. 48-54.

[11] Sihotang, Hengki Tamando. "Sistem Pakar Mendiagnosa Penyakit Kolesterol Pada Remaja Dengan Metode Certainty Factor ( Cf ) Berbasis Web." Jurnal Mantik Penusa, vol. 15, no. 1, 2014, pp. 16-23.

[12] Sihotang, Hengki Tamando, and Maria Siboro. "Aplikasi Sistem Pendukung Keputusan Penentuan Siswa Bermasalah Menggunakan Metode Saw Pada Sekolah Smp Swasta Mulia Pratama Medan.” Journal of Informatics Pelita Nusantara, vol. 1, no. 1, 2016, pp. 1-6.

[13] Simangunsong, Agustina, et al. "Perancangan Aplikasi Sistempakar Menggunakan Metode Bayes Untuk Diagnosa Gejala Asma Pada Puskesmas Deli Tua." Journal of Informatics Pelita Nusantara, vol. 2, no. 1, 2017, pp. 14-21, http://e-

jurnal.pelitanusantara.ac.id/index.php/JIPN/ article/view/273/171. 